\title{
A Narrative Review of Microsporidial Infections of the Cornea
}

\author{
Majid Moshirfar (D) - Shaan N. Somani - Kathryn M. Shmunes • \\ Ladan Espandar · Nikhil S. Gokhale • Yasmyne C. Ronquillo • \\ Phillip C. Hoopes
}

Received: January 12, 2020 / Published online: March 10, 2020

(C) The Author(s) 2020, corrected publication 2021

\section{ABSTRACT}

Microsporidia are a rare and commonly misdiagnosed cause of corneal infection, accounting for approximately $0.4 \%$ of cases of microbial keratitis in some populations. Ocular microsporidiosis most often presents as either microsporidial keratoconjunctivitis (MKC) or microsporidial stromal keratitis (MSK). Though these two clinical entities exhibit similar symptomology, they are distinguished from one another by the time course for disease

Enhanced Digital Features To view enhanced digital features for this article go to https://doi.org/10.6084/ m9.figshare.11902305.

M. Moshirfar $(\bowtie) \cdot$ K. M. Shmunes .

Y. C. Ronquillo - P. C. Hoopes

Hoopes Vision Research Center, Draper,

UT, USA

e-mail: Cornea2020@me.com

M. Moshirfar

John A. Moran Eye Center, University of Utah

School of Medicine, Salt Lake City,

UT, USA

M. Moshirfar

Utah Lions Eye Bank, Murray,

UT, USA progression, findings on slit-lamp examination, and response to medical therapy. This review summarizes the current literature on the etiology and clinical presentation of microsporidial infections of the cornea and highlights ongoing developments in available diagnostic modalities and treatment regimens.

Keywords: Keratoconjunctivitis; Microsporidiosis; Stromal keratitis

\author{
S. N. Somani \\ Northwestern Feinberg School of Medicine, \\ Chicago, IL, USA \\ L. Espandar \\ Sightline Ophthalmic Associates, Pittsburgh, PA, \\ USA \\ N. S. Gokhale \\ Gokhale Eye Hospital, Dadar West, Mumbai, India
}




\section{Key Summary Points}

Microsporidia are unicellular, eukaryotic parasites that may rarely cause ocular infections, most often following ocular trauma or exposure to contaminated water.

Ocular microsporidiosis typically presents as either acute keratoconjunctivitis or insidious stromal keratitis.

The coarse, multifocal, raised epithelial infiltrates seen on slit-lamp examination of microsporidial keratoconjunctivitis are a key distinguishing feature from other more common causes of ocular infection.

Light microscopy of tissue scrapings is the most common technique for the diagnosis of ocular microsporidiosis in the modern era.

Various pharmacotherapy regimens have been described as effective in treating microsporidial keratoconjunctivitis; conversely, microsporidial stromal keratitis is typically resistant to antimicrobial therapy and most often requires surgical excision of affected tissue with corneal graft transplantation.

\section{INTRODUCTION}

Microsporidia are unicellular, obligate intracellular, eukaryotic parasites that belong to the phylum Microspora and subkingdom Protista $[1,2]$. Microsporidia are true eukaryotes due to the presence of a nucleus with a nuclear envelope, chromosome separation on mitotic spindles, and an intracytoplasmic membrane system [3]. Unlike most eukaryotes, however, microsporidia lack typical mitochondria, peroxisomes, and centrioles. Moreover, they possess some "prokaryotic" characteristics such as tiny genomes, $70 \mathrm{~S}$ ribosomes, and a fused $5.8 \mathrm{~S}$ and $28 \mathrm{~S}$ rRNA; for these reasons, they were once classified as protozoans, but are now considered closely related to fungi [4].

Since their discovery in 1857 in silkworms, over 1300 species of microsporidia belonging to nearly 200 genera have been described $[5,6]$. Seven genera (Enterocytozoon species, Brachiola species, Encephalitozoon species, Pleistophora species, Nosema species, Vittaforma species, and Trachipleistophora species) as well as unclassified microsporidia, collectively referred to as $\mathrm{Mi}$ crosporidium, have been associated with human disease [7]. Microsporidia are opportunistic pathogens that have been implicated in infections of the intestines, eyes, sinuses, lungs, muscles, kidneys, and central nervous system [7]. Besides infections of the digestive tract, ocular disease is the second most common clinical manifestation of microsporidia [4]. In certain populations, microsporidia account for approximately $0.4 \%$ of cases of microbial keratitis [8]. The purpose of this review is to summarize the existing literature on the etiology, clinical presentation, diagnosis, and treatment of microsporidial infections of the cornea.

\section{METHODOLOGY}

A search of the literature was undertaken in October 2019 using PubMed without dates of exclusion. We included all English language papers related to microsporidial infections of the cornea. Foreign language articles were not included. The search terms used were microsporidiosis, stromal keratitis, ocular infection, keratoconjunctivitis, and various combinations of these terms. This article is based on previously conducted studies and does not contain any studies with human participants or animals performed by any of the authors.

\section{PATHOPHYSIOLOGY}

The characteristic feature of microsporidia is the intracellular spore, which confers resistance to adverse environmental conditions and promotes dissemination [9]. The spore length is typically between 2 and $8 \mu \mathrm{m}$ but varies across 
species, ranging from 1 to $30 \mu \mathrm{m}$ [10]. The cell wall of the spore is composed of a double envelope, of which the outer part contains glycoproteins and the inner part is primarily composed of chitin [11]. Within the endospore lies the sporoplasm, the infectious element formed by the cytoplasm and one or two nuclei [12]. Microsporidia infect host cells via an ejection apparatus known as the polar filament; different stimuli such as changes in $\mathrm{pH}$, exposure to certain cations, or low-dose ultraviolet radiation can induce extrusion of the polar filament, which subsequently injects the sporoplasm into the cytoplasm of the host cell $[13,14]$. Once inside the host cell, the sporoblast divides by binary fission to form schizonts with two to six nuclei. The schizonts split into unicellular meronts, which secrete a rigid capsule and attain the final size of $2.5 \times 1.5 \mu \mathrm{m}$. The meronts further differentiate into sporonts and spores; when the cell eventually ruptures, these newly formed spores repeat the cycle to infect nearby host cells [15].

The mechanism by which microsporidial corneal infections occur remains unclear. Nonetheless, given that microsporidia are waterborne pathogens, direct inoculation through exposure to contaminated water in hot springs, rivers, and swimming pools has been implicated [16-18]. One retrospective case series found that $50 \%$ of patients had ocular exposure to muddy water [19]; another case series found that $47 \%$ endorsed a history of ocular trauma, though the degree of damage to the corneal epithelium was not noted [20]. Contact lenses may act as a vector by which the organism reaches the cornea; therefore, contact lens wear, especially in the setting of poor lens hygiene, is an important predisposing factor [21]. Microsporidial corneal infections have rarely arisen following ocular surgeries, including laser in situ keratomileusis (LASIK), Descemet stripping automated endothelial keratoplasty (DSAEK), penetrating keratoplasty (PK), and collagen cross-linking (CXL) [22-25]. A few outbreaks of ocular microsporidiosis in rugby players have been reported, likely secondary to exposure to contaminated soil on the playing field $[26,27]$. Other risk factors include topical corticosteroid use, insect bites, and contact with domestic animals $[4,28,29]$. Most cases of microsporidial corneal infections have occurred in South and Southeast Asian countries; a higher incidence has been noted during the monsoon period from July to October, which is speculated to be related to contamination of water with microsporidia or an increase in the insect population [19, 30, 31].

\section{CLINICAL PRESENTATION}

The first reported case of ocular microsporidiosis was in an 11-year-old Sri Lankan boy in 1973 by Ashton and Wirasinha [32]. Microsporidial corneal infections may present as an isolated infection or as part of systemic disease [33]. Though some case reports exist on scleritis [34] and endophthalmitis [35, 36] secondary to microsporidia, ocular microsporidiosis most often presents as one of two forms: superficial keratoconjunctivitis or stromal keratitis (Table 1).

\section{Microsporidial Keratoconjunctivitis}

Throughout the 1990s, multiple cases of microsporidial keratoconjunctivitis (MKC) were diagnosed in individuals with immunosuppression secondary to acquired immunodeficiency syndrome (AIDS) [37-39]. Since then, numerous reports of MKC in healthy, immunocompetent adults have arisen over the past 2 decades $[21,40,41]$. The worldwide prevalence of MKC is on the rise due to increased awareness; nonetheless, most cases go undiagnosed or misdiagnosed as atypical adenoviral keratoconjunctivitis [42].

MKC most often occurs secondary to Encephalitozoon species and causes a self-limiting disease in immunocompetent patients [15]. Patients generally present with photophobia, redness, tearing, foreign body sensation, impaired visual acuity, and eye pain within 1 week of symptom onset [4, 31, 42]. A recent study by Wang et al. proposed that the pattern of lesions on slit-lamp examination may represent different stages of disease maturation [17]. The initial stage is characterized by a mild to severe non-purulent conjunctivitis and grayish- 
Table 1 Characteristics of microsporidial keratoconjunctivitis and stromal keratitis

\begin{tabular}{|c|c|c|}
\hline & Microsporidial keratoconjunctivitis (MKC) & Microsporidial stromal keratitis (MSK) \\
\hline Risk factors & \multicolumn{2}{|c|}{$\begin{array}{l}\text { Exposure to contaminated water or soil }[16-18,26,27] \text {, ocular trauma }[20] \text {, contact lens wear }[21] \text {, ocular } \\
\text { surgeries }[22-25] \text {, topical steroid use [4], insect bites [28], contact with domestic animals [29] }\end{array}$} \\
\hline $\begin{array}{l}\text { Time to } \\
\text { presentation }\end{array}$ & Acute $[42]$ & Delayed [3] \\
\hline $\begin{array}{l}\text { Clinical } \\
\text { presentation }\end{array}$ & \multicolumn{2}{|c|}{ Photophobia, redness, tearing, foreign body sensation, impaired visual acuity, eye pain $[4,31,42]$} \\
\hline $\begin{array}{l}\text { Slit-lamp } \\
\text { findings }\end{array}$ & $\begin{array}{l}\text { Grayish-white, coarse, multifocal, raised epithelial } \\
\text { lesions and non-purulent } \\
\text { conjunctivitis } \rightarrow \text { central epithelial } \\
\text { lesions } \rightarrow \text { superficial punctate } \\
\text { keratopathy } \rightarrow \text { subepithelial infiltrates or haze } \\
{[17]}\end{array}$ & $\begin{array}{l}\text { Diffuse multifocal stromal infiltrates, non-purulent } \\
\text { conjunctivitis, stromal edema, endothelial exudates; } \\
\text { rarely, epithelial defects [20] }\end{array}$ \\
\hline $\begin{array}{c}\text { Differential } \\
\text { diagnosis }\end{array}$ & $\begin{array}{l}\text { Thygeson's superficial punctate keratitis [44], } \\
\text { Acanthamoeba keratitis [43], mycobacterial } \\
\text { keratitis [21], adenoviral keratoconjunctivitis } \\
\text { [40] }\end{array}$ & Fungal, bacterial, or HSV stromal keratitis [23] \\
\hline $\begin{array}{l}\text { Diagnostic } \\
\text { techniques }\end{array}$ & \multicolumn{2}{|c|}{$\begin{array}{l}\text { Transmission electron microscopy (TEM) [4], light microscopy (LM) } \pm \text { tissue staining }[50] \text {, } \\
\text { histopathology }[4] \text {, polymerase chain reaction (PCR) }[50] \text {, in vivo confocal microscopy (IVCM) }[4,6] \text {, } \\
\text { anterior segment optical coherence tomography (AS-OCT) }[4,5]\end{array}$} \\
\hline $\begin{array}{l}\text { Treatment } \\
\text { options }\end{array}$ & $\begin{array}{l}\text { Self-limiting [66]; most often treated with mono- } \\
\text { or combination therapy consisting of topical } \\
\text { fumagillin [7], oral albendazole [55], topical } \\
\text { antibiotics [60], topical antifungals [62], and/or } \\
\text { topical antiseptics [66] }\end{array}$ & $\begin{array}{l}\text { Usually requires corneal graft transplantation }[71] \\
\text { though some reports exist of resolution with } \\
\text { medical therapy alone }[20,68-70]\end{array}$ \\
\hline Prognosis & Excellent [56] & Guarded $[6,8]$ \\
\hline
\end{tabular}

white, coarse, multifocal, raised epithelial lesions (Fig. 1). The resolution of peripheral lesions and conjunctivitis occurs within 1 week but is closely followed by the development of central epithelial lesions and superficial punctate keratopathy. Epithelial lesions resolve within 2 to 4 weeks, after which subepithelial infiltrates or haze may form (Fig. 2). Notably, not all stages are seen in every patient, but the natural progression follows the above pattern [17]. Rarely, mucopurulent discharge and regional lymph node involvement may be seen [18].

\section{Microsporidial Stromal Keratitis}

Microsporidial stromal keratitis (MSK) is rarer than superficial keratoconjunctivitis and occurs predominantly in immunocompetent individuals. MSK follows a slow-growing, insidious course, with symptoms ranging from 1 month to 2 years prior to the initial presentation [3]. MSK typically occurs secondary to Vittaforma corneae (previously Nosema corneum) or Microsporidium [15, 43]. MSK manifests symptomatically as unilateral ocular pain, conjunctival redness, photophobia, impaired visual acuity, and foreign body sensation. Slit- 


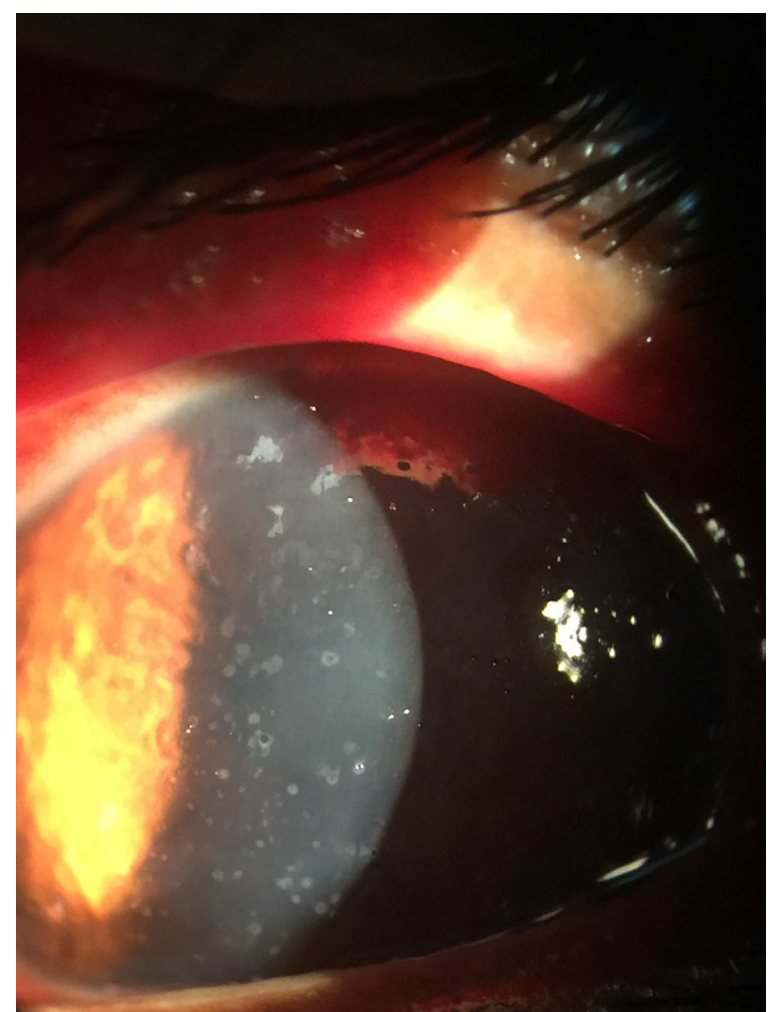

Fig. 1 Microsporidial keratoconjunctivitis (Photo from Dr. Nikhil S. Gokhale)

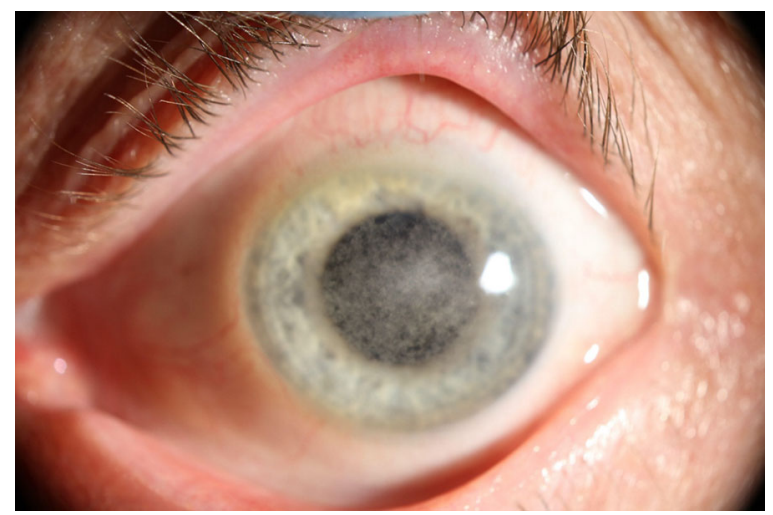

Fig. 2 Microsporidial keratoconjunctivitis (Photo from Dr. Ladan Espandar)

lamp biomicroscopy of MSK most often reveals diffuse multifocal mid- to deep stromal infiltrates with mild to moderate conjunctival injection, stromal edema, and endothelial exudates. The overlying epithelium is typically intact, though rarely epithelial defects may be visible over the stromal lesions (Fig. 3) [20].

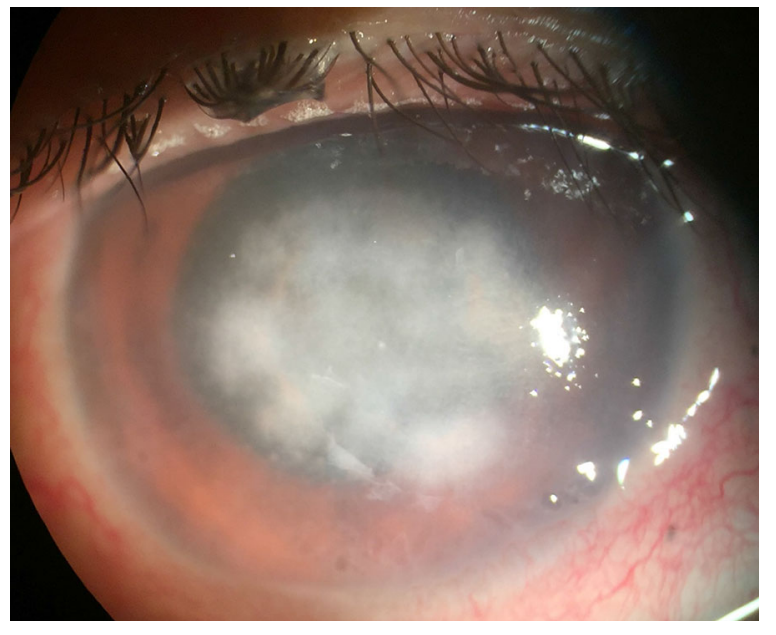

Fig. 3 Microsporidial stromal keratitis (Photo from Dr. Nikhil S. Gokhale)

\section{DIFFERENTIAL DIAGNOSIS}

Due to the rarity of microsporidia as a cause of corneal infection and the lack of characteristic clinical examination findings, both MKC and MSK are frequently misdiagnosed. Namely, the multifocal epitheliopathy seen in MKC may be confused for Thygeson's superficial punctate keratitis [44], Acanthamoeba keratitis [43], mycobacterial keratitis [21], or viral keratoconjunctivitis [40]; however, the multifocal, coarse, raised epithelial infiltrates seen in MKC are a key distinguishing feature from the above listed clinical entities. Furthermore, subepithelial lesions seen in MKC are larger than the nummular infiltrates present in viral keratoconjunctivitis [45]. In contrast to MKC, adenoviral keratoconjunctivitis is often characterized by an increased number of dendritic cells in the central cornea due to the activation of the innate immune system [46].

MSK may closely resemble fungal, bacterial, or HSV keratitis, leading to further delays in diagnosis [23]. Rarely, MSK may be mistaken for Acanthamoeba keratitis [47]. One case series of 34 patients with MSK found that $38.2 \%$ and $32.3 \%$ of patients were initially diagnosed with HSV stromal keratitis and fungal keratitis, respectively. Consequently, the mean duration between the initial presentation and final diagnosis in this study was $94.0 \pm 232.2$ days [20]. 
The major clues towards a diagnosis of MSK are an unsatisfactory initial response to corticosteroids and characteristic appearance of the stromal infiltrate that does not resemble bacterial or fungal infections. Moreover, patients with MSK are unlikely to present with deep vascularization with stromal scarring, a common feature in HSV stromal keratitis [20].

Ultimately, microsporidia are best identified through an examination of morphologic features in tissue studies; thus, the clinician must have a high index of suspicion to include microsporidia in the differential [15].

\section{DIAGNOSIS}

Microsporidia are often difficult to detect since they are obligate intracellular organisms and require specific cell culture systems for growth [46]. The diagnosis of microsporidial corneal infections most often hinges on morphologic identification of organisms on tissue scrapings; however, due to their small size, microsporidia may still evade detection on microscopy. Therefore, several molecular and non-invasive techniques may aid in the diagnosis.

\section{Transmission Electron Microscopy}

Transmission electron microscopy (TEM) was long regarded as the gold standard for the identification of microsporidia. Organisms may be definitively classified as a member of the phylum Microspora by the presence of a polar tubule on TEM. TEM is further capable of differentiating species based on their ultrastructural characteristics. Vittaforma corneae, which most often causes MSK but has been implicated in some cases of MKC, is identified by a spore size of $3-5 \mu \mathrm{m}$ and $11-13$ coils in the polar tubule. Conversely, Encephalitozoon species, which typically cause MKC, are identified by 2-3 $\mu \mathrm{m}$ spores and contain $4-7$ coils in the polar tubule; moreover, they are characterized by the presence of a parasitophorous vacuole surrounding the organism in the host cell [15]. The identification of specific Microsporidia species may be useful for tailoring treatment regimens and determining prognosis. However, TEM is not often used as an initial screening tool in the modern era as it is time-consuming, not routinely available, and carries a lower relative sensitivity due to the small amount of tissue that can be examined [4].

\section{Light Microscopy}

Light microscopy is the most common technique for the detection of microsporidia in the modern era. Alcohol-fixed cytologic samples have proven useful for the detection of microsporidial blastospores [48]. Various stains are available that may increase the sensitivity of microscopic examination. On Weber's modified trichrome stain, microsporidia spore walls appear bright pinkish-red against a blue or faint green background, sometimes with a belt-like stripe that encircles the spores equatorially or diagonally [49]. Gram stain may be useful for identification of mature spores but should only be used on specimens with little debris to reduce potential false positives (Fig. 4). Giemsa stain carries the advantage of making the nuclei visible and revealing developmental stages; however, it has low sensitivity and is not

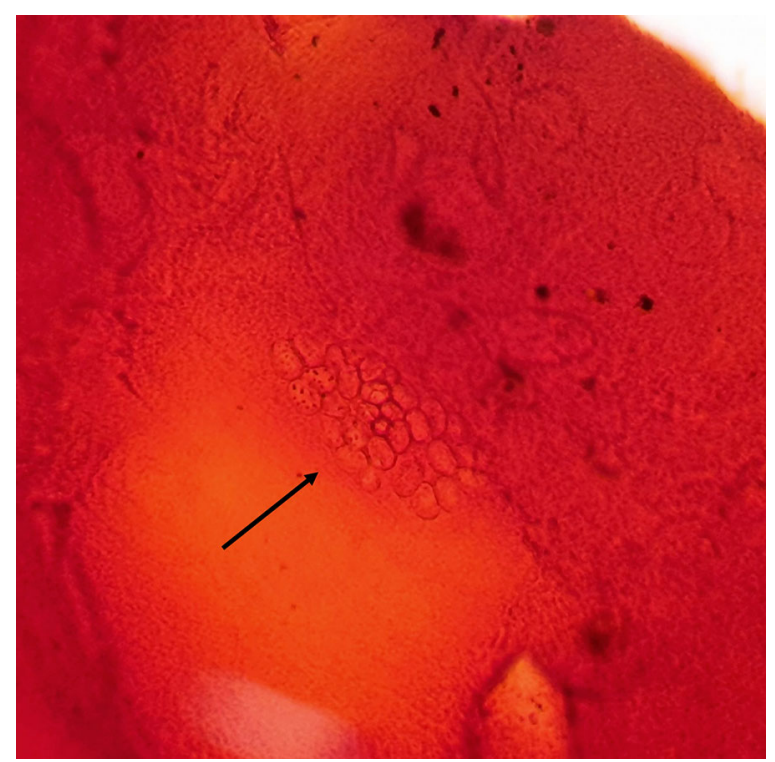

Fig. 4 Microsporidial spores are seen as clusters of unstained halos in gram stain of the corneal scraping (black arrow) (Photo from Dr. Jyoti Prakash Panda. Gram's, × 100) 


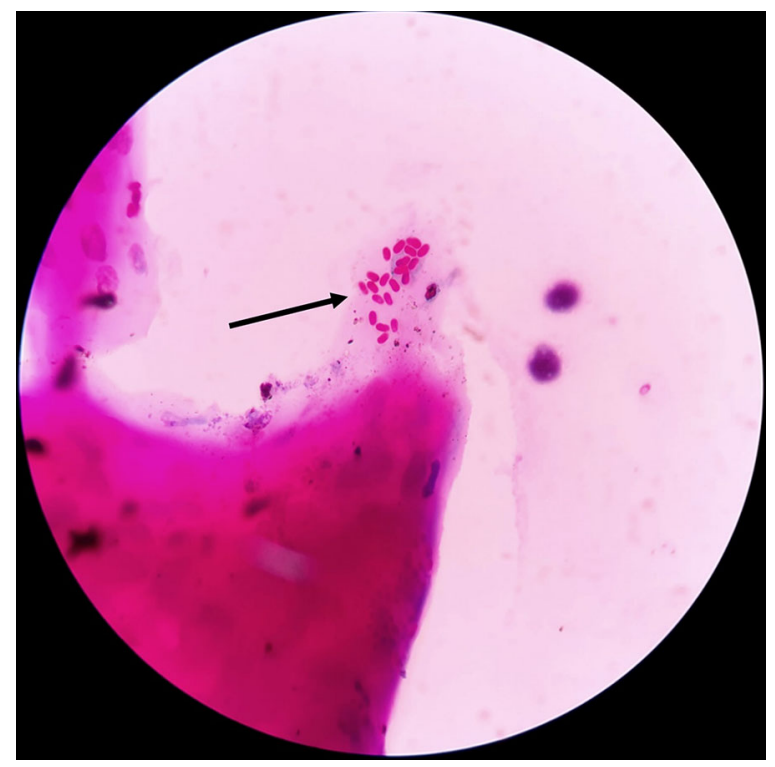

Fig. 5 Modified Ziehl-Nielsen stain of microsporidia. Oval reddish-pink microsporidia are present (black arrow) (Photo from Dr. Jyoti Prakash Panda. 1\% Acid-fast, modified $\mathrm{ZN}, \times 100)$

recommended for routine use [4]. Modified Ziehl-Neelsen (acid-fast) stain is highly sensitive, but not always readily available in many clinical practices (Fig. 5). A study by Joseph et al. determined a sensitivity of $90.3 \%$ with gram stain, $64.5 \%$ with Giemsa stain, and $87 \%$ with modified acid-fast stain for the detection of microsporidia [50]. Chitin in the cell wall of spores appears bright when stained with fluorescent agents such as calcofluor white, Uvitex $2 \mathrm{~B}$, or Fungi-Fluor. These agents are rapid and sensitive, though many other structures such as fungal spores may give false-positive results [51]. The sensitivity of potassium hydroxide with calcofluor white was found in one study to be 93.5\% [50]. The major drawback of light microscopy as a diagnostic technique is that the interpretation of slides is time-consuming, requires an experienced observer, and does not allow for the identification of specific species.

\section{Histopathology}

Routine histopathology is occasionally attempted in the detection of microsporidia. Modified trichrome, modified Ziehl-Neelsen, and modified gram stains are generally sensitive and recommended for this purpose. Detection of microsporidia on hematoxylin and eosin (H\&E) and Giemsa stains is largely dependent on the experience of the pathologist and carries variable accuracy if there are a low number of parasites in the specimen [4].

Some immunofluorescent antibody techniques have been developed for the detection of Encephalitozoon species spores, though they are less convenient compared with traditional chromotrope and fluorochromes. Moreover, reagents for immunofluorescence staining of microsporidial spores may have low specificity because of background staining and cross-reactions with yeast and bacteria [3]. Lastly, these techniques are not yet readily available in many laboratory settings.

\section{Polymerase Chain Reaction}

Molecular identification is a rapid, low-cost diagnostic technique that allows for the identification of most species implicated in ocular infections. Polymerase chain reaction (PCR) most often uses small-subunit rRNA sequences for species-specific detection [7, 50]. Two different PCR primers for detection of microsporidia have been described in the literature: a PCR-1 primer with a DNA fragment length of 1150 bp [52], and a PCR-2 primer with a DNA fragment length of $250 \mathrm{bp}$ [53]. The PCR-2 primer was demonstrated by Joseph et al. to carry a sensitivity and specificity of $83 \%$ and $98 \%$, respectively [50]. Wang et al. found the PCR-2 primer to be more sensitive than the PCR-1 primer; these authors hypothesized that as a result of the longer DNA fragment length, there may be an increased number of replication errors introduced by Taq polymerase [17]. Another novel technique described by Polley et al. used the SYBR Green real-time PCR assay to identify individual Microsporidia species [54]. Though advancements in PCR technology continue to emerge, PCR alone should not be used for the detection of microsporidia because of a lower relative sensitivity than other described techniques. 


\section{Non-Invasive Techniques}

All diagnostic procedures described thus far rely upon corneal scraping or biopsy, which unavoidably creates an epithelial defect. Although rare, corneal scraping may result in significant corneal abrasions, which subsequently cause patient discomfort and delay visual rehabilitation [45]. Of more serious concern is that the process of scraping corneal tissue may facilitate deeper penetration, converting potentially self-limiting keratoconjunctivitis to treatment-resistant stromal keratitis. Furthermore, the accuracy of the above techniques largely depends on the amount and distribution of organisms obtained from the corneal scraping, the staining process, and the diagnostic skills of the observer [43]. In vivo confocal microscopy (IVCM) and anterior segment optical coherence tomography (AS-OCT) are two novel diagnostic methods that preclude the need for corneal scrapings.

IVCM relies upon the Heidelberg Retina Tomograph (HRT II), a 670-nm wavelength diode laser, to produce in vivo images of the anterior segment. IVCM of MKC reveals multiple rosette-like clusters of epithelial cells in which spores are visualized as hyperreflective, pinpoint oval intracellular bodies [46]. In stromal keratitis, spores tend to align along lamellae [55]. The absence of a significantly increased number of dendritic cells in the deeper epithelial layers is particularly helpful in distinguishing microsporidial keratoconjunctivitis from adenoviral infection [46]. IVCM is also useful for monitoring response to medical therapy [55]. The specificity and sensitivity of IVCM in detecting microsporidia has not been reported in the literature; nonetheless, some authors have recommended that IVCM be adopted as a first-line screening tool [46].

AS-OCT is a non-invasive, high-resolution technique that uses a 1050-nm wavelength light source to scan the entire cornea with a radial pattern within one frame (Fig. 6). A single prospective study found that all 13 patients with MKC exhibited hyperreflective dots limited to the epithelial layers of the cornea on ASOCT. AS-OCT is especially useful for distinguishing $\mathrm{MKC}$ from viral keratoconjunctivitis, which is more likely to present with a smooth epithelial surface and hyperreflective lesions in the subepithelial layer that extend to the anterior stroma. The authors of this study concluded that although AS-OCT could not serve as the gold standard for diagnosis, it may guide treatment, especially in conditions in which corneal scraping is not otherwise possible [45].

\section{TREATMENT/MANAGEMENT}

\section{MKC}

There remains no consensus on medical treatment for MKC; as such, various therapeutic regimens have been attempted. Response to medical therapy is highly dependent upon the species involved and the immune status of the patient [9]. In most case, the visual prognosis is good with no loss of visual acuity after MKC resolution [56].

Of all available medications, fumagillin and albendazole have demonstrated the most antimicrosporidial activity in vitro [57]. Fumagillin is a water-insoluble antibiotic that has been used extensively. The mechanism of action of fumagillin is not entirely understood, but it is believed to alter DNA content or inhibit RNA synthesis in the organism [15]. One study found that topical fumagillin bicylohexylammonium (Fumidil B) $3 \mathrm{mg} / \mathrm{ml}$, equivalent to $70 \mu \mathrm{g} / \mathrm{ml}$ fumagillin, used topically every hour during daytime for 7 days allowed MKC symptoms to subside; however, because fumagillin is parasitistatic rather than parasiticidal, symptoms may return upon discontinuation of topical Fumidil B [7]. Albendazole is a broadspectrum antihelminthic that inhibits microtubule formation and has shown clinical efficacy in the treatment of microsporidial corneal infections [2, 58]. Albendazole is most commonly prescribed as $400 \mathrm{mg}$ oral tablets to be taken once or twice daily as monotherapy or in combination with fumagillin [55]. Of note, albendazole may have limited efficacy against certain species of microsporidia such as Enterocytozoon bieneusi, reinforcing the importance of designing a species-specific treatment regimen $[35,59]$. 


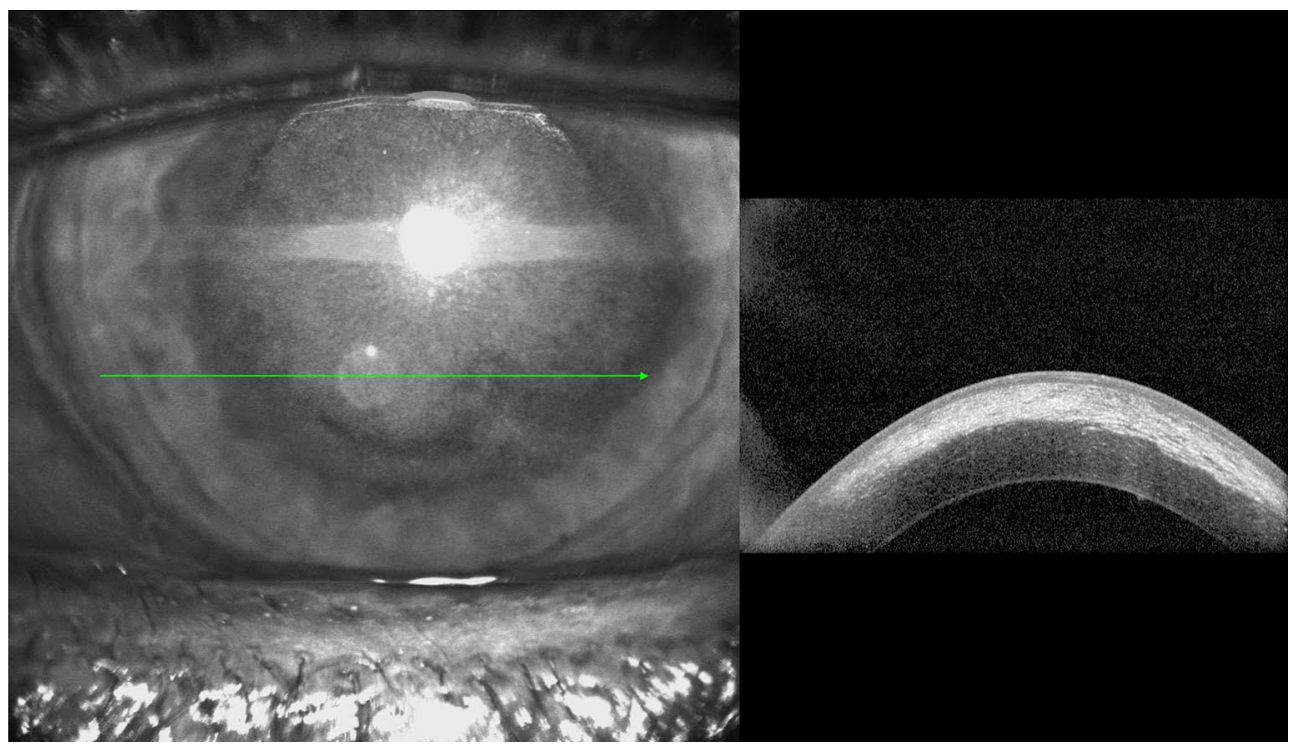

Fig. 6 Anterior segment optical coherence tomography demonstrating stromal haze involving the anterior half of the cornea with normal epithelial integrity (Photo from Dr. Ladan Espandar)

Several other treatment regimens have been described. Topical fluoroquinolone monotherapy (moxifloxacin 0.5\%, ciprofloxacin 0.3\%, norfloxacin $0.3 \%$, etc.) six or more times daily has resulted in sustained symptom resolution without disease recurrence $[45,60]$. One study of 134 eyes found complete symptom resolution in $99 \%$ of patients on fluoroquinolone monotherapy [19]. Other studies have used a combination of topical fluoroquinolones with topical voriconazole $1 \%$ six times daily [46], $0.1 \%$ betamethasone $0.1 \%$ twice daily [17], topical propamidine isethionate $0.1 \%$ every hour [27], or oral albendazole $400 \mathrm{mg}$ twice daily [25]. Alternatively, some physicians prefer topical fluconazole $0.3 \%$ six times daily as monotherapy or in combination with $0.3 \%$ ciprofloxacin ointment $[29,42,61]$. Khandelwal et al. found that topical voriconazole $1 \%$ monotherapy every $2 \mathrm{~h}$ led to complete resolution of MKC in two patients [62]. Topical propamidine isethionate $0.1 \%$ six times daily monotherapy and oral itraconazole $100 \mathrm{mg}$ twice daily monotherapy have previously been described, though these regimens do not appear to be commonly employed in the modern era [39, 63-65]. Regardless of which antimicrobial therapy is elected, treatment is generally tapered with clinical improvement over several weeks to months.

Notably, there is some question as to whether antimicrobial therapy or debridement is necessary given the self-limiting nature of MKC. A randomized controlled trial by Das et al. found no significant difference in time to resolution between patients with MKC who were treated with polyhexamethylene biguanide (PHMB) $0.02 \%$ every $4 \mathrm{~h}$ or placebo [66]. Another study found that all patients with MKC who underwent debridement achieved resolution without recurrence regardless of the medication regimen, suggesting that debridement of the epithelium plays the most significant role in treatment [8]. Conversely, a randomized clinical trial found no significant difference in the final visual outcome and resolution time between patients who underwent debridement and those who did not; notably, none of the patients in this study received antimicrobial therapy [67]. There is some evidence to suggest that repeat corneal swabbing without the use of debridement is sufficient to eradicate epithelial microsporidial lesions [44]. Debridement increases the risk that pathogens may penetrate the deep stromal layers and convert a self-limiting MKC to a treatment-resistant MSK; as such, some authors advise that if debridement is 
performed, it should be accompanied by prophylactic topical antimicrobials to prevent subsequent microsporidial or bacterial growth $[27,44]$.

Most authors do not recommend the use of topical corticosteroids as this may allow for persistent infection due to the promotion of a local immunocompromised state [40]; however, some feel that steroids are warranted to prevent the subsequent formation of nummular keratitis, stromal haze, or uveitis [17]. Agashe et al. found in their retrospective case series of 550 patients with MKC that $10.1 \%$ developed nummular keratitis and 1\% developed uveitis; in these cases, tapered treatment with topical steroids (fluorometholone $0.1 \%$ or prednisolone acetate $1 \%$ ) is warranted until complete resolution of the infection is achieved [16].

\section{MSK}

MSK carries a poor prognosis and tends to be resistant to medical therapy [68], though a few cases exist of successful treatment with a combination of topical and systemic antimicrobials. Sangit, Murthy, and Garg were the first to describe a case of MSK that was responsive to medical therapy; a combination of $0.02 \%$ topical chlorhexidine gluconate hourly and $400 \mathrm{mg}$ oral albendazole twice daily given for 12 weeks resulted in complete resolution in a 14-year-old girl [69]. Another case report described the resolution of MSK following dual therapy of topical voriconazole $1 \%$ daily and oral itraconazole $200 \mathrm{mg}$ twice daily for 8 weeks [68]. Five patients in a case series by Sabhapandit et al. responded to combination therapy with $\mathrm{PHMB}$ $0.02 \%$ and chlorhexidine $0.02 \%$ every half to 1 hour and oral albendazole $400 \mathrm{mg}$ twice daily [20]. The most recent report by Grillo et al. found that MSK subsided following albendazole $400 \mathrm{mg}$ once daily over 2 weeks and topical voriconazole $1 \%$ and fumagillin $3 \mathrm{mg} / \mathrm{ml}$ eye drops over 10 weeks [70].

Though these initial findings are intriguing, most reported cases of MSK have gone on to require surgical excision of tissue with corneal graft transplantation [71]. Most authors recommend PK over lamellar keratoplasty to avoid any chance of recurrence in the lamellar bed [68]. Notably, Ang et al. described a case in which deep anterior lamellar keratoplasty (DALK) allowed for visual rehabilitation in a woman with severe MSK [72]. However, Sabhapandit et al. found that all patients who underwent DALK in their case series experienced MSK recurrence and required $\mathrm{PK}$ at a later time [20]. Overall, PK remains the gold standard for the treatment of MSK, but greater insight into the ideal treatment regimen will emerge as MSK becomes more frequently recognized.

\section{CONCLUSION}

Microsporidia are a rare cause of corneal infections that most often present as acute superficial keratoconjunctivitis secondary to Vittaforma corneae or slow-growing, recalcitrant stromal keratitis secondary to Encephalitozoon species. Though ocular microscopy and tissue staining remain the most common tools for the detection of Microsporidia, molecular and non-invasive techniques may play an expanding role in the diagnosis. The ideal treatment regimen for microsporidial corneal infections remains unclear, especially given the self-limiting nature of MKC. Topical fumagillin and oral albendazole are among the most commonly used antimicrobials, but a variety of regimens have been described. A few cases of MSK have responded to medical therapy, but the majority of patients require corneal graft transplantation. As physicians become more aware of microsporidia as a potential cause for corneal infection, new insights into the optimal therapeutic regimen will continue to arise.

\section{ACKNOWLEDGEMENTS}

Dr. Jyoti Prakash Panda of the Microbiology Department, P.D. Hinjujha Hospital, Mahim, Mumbai, is acknowledged for the use of the microbiology slides of microsporidia.

Funding. This review was funded by an unrestricted grant from Research to Prevent 
Blindness (RPB), 360 Lexington Avenue, 22nd Floor New York, NY 10017. No support was received for the publication of this article.

Authorship. All named authors meet the International Committee of Medical Journal Editors (ICMJE) criteria for authorship for this article, take responsibility for the integrity of the work as a whole, and have given their approval for this version to be published.

Disclosures. Majid Moshirfar, Shaan N Somani, Kathryn M Shmunes, Ladan Espandar, Nikhil S Gokhale, Yasmyne C Ronquillo, and Phillip C Hoopes declare that they have no conflict of interest.

Compliance with Ethics Guidelines. This article is based on previously conducted studies and does not contain any studies with human participants or animals performed by any of the authors.

Data Availability. Data sharing is not applicable to this article as no datasets were generated or analyzed during the current study.

Open Access. This article is licensed under a Creative Commons Attribution-NonCommercial 4.0 International License, which permits any non-commercial use, sharing, adaptation, distribution and reproduction in any medium or format, as long as you give appropriate credit to the original author(s) and the source, provide a link to the Creative Commons licence, and indicate if changes were made. The images or other third party material in this article are included in the article's Creative Commons licence, unless indicated otherwise in a credit line to the material. If material is not included in the article's Creative Commons licence and your intended use is not permitted by statutory regulation or exceeds the permitted use, you will need to obtain permission directly from the copyright holder. To view a copy of this licence, visit http://creativecommons.org/licenses/by$\mathrm{nc} / 4.0 /$.

\section{REFERENCES}

1. Keeling P. Five questions about microsporidia. PLoS Pathog. 2009. https://doi.org/10.1371/journal.ppat. 1000489 .

2. Franzen C, Müller A. Molecular techniques for detection, species differentiation, and phylogenetic analysis of microsporidia. Clin Microbiol Rev. 1999. https://doi.org/10.1128/cmr.12.2.243.

3. Bhosale NK, Ganesan N. Microsporidial keratitis. J Bacteriol Parasitol. 2015;06(06):5-8. https://doi. org/10.4172/2155-9597.1000248.

4. Sharma S, Das S, Joseph J, Vemuganti GK, Murthy S. Microsporidial keratitis: need for increased awareness. Surv Ophthalmol. 2011;56(1):1-22. https:// doi.org/10.1016/j.survophthal.2010.03.006.

5. Didier ES, Stovall ME, Green LC, Brindley PJ, Sestak $\mathrm{K}$, Didier PJ. Epidemiology of microsporidiosis: sources and modes of transmission. Vet Parasitol. 2004. https://doi.org/10.1016/j.vetpar.2004.09.006.

6. Vávra J, Lukeš J. Microsporidia and 'The Art of Living Together'. Adv Parasitol. 2013;82:253-319. https://doi.org/10.1016/B978-0-12-407706-5. 00004-6.

7. Weber R, Bryan RT, Schwartz DA, Owen RL. Human microsporidial infections. Clin Microbiol Rev. 1994. https://doi.org/10.1128/CMR.7.4.426.

8. Joseph J, Sridhar MS, Murthy S, Sharma S. Clinical and Microbiological profile of Microsporidial keratoconjunctivitis in Southern India. Ophthalmology. 2006;113(4):531-7. https://doi.org/10.1016/j. ophtha.2005.10.062.

9. Leroy J, Cornu M, Deleplancque AS, et al. Case report: ocular Microsporidiosis: case in a patient returning from India and review of the literature. Am J Trop Med Hyg. 2018;99(1):90-3. https://doi. org/10.4269/ajtmh.18-0015.

10. Stentiford GD, Becnel JJ, Weiss LM, et al. Microsporidia-emergent pathogens in the global food chain. Trends Parasitol. 2016. https://doi.org/10. 1016/j.pt.2015.12.004.

11. Didier ES. Microsporidiosis: an emerging and opportunistic infection in humans and animals. Acta Trop. 2005. https://doi.org/10.1016/j. actatropica.2005.01.010.

12. Keeling PJ, Fast NM. Microsporidia: biology and evolution of highly reduced intracellular parasites. Annu Rev Microbiol. 2002. https://doi.org/10.1146/ annurev.micro.56.012302.160854. 
13. Bigliardi E, Sacchi L. Cell biology and invasion of the microsporidia. Microbes Infect. 2001. https:// doi.org/10.1016/S1286-4579(01)01393-4.

14. Xu Y, Weiss LM. The microsporidian polar tube: a highly specialised invasion organelle. Int J Parasitol. 2005. https://doi.org/10.1016/j.ijpara.2005. 04.003.

15. Alkatan HM, Al-Zaaidi S, Athmanathan S. Microsporidial keratitis: literature review and report of 2 cases in a tertiary eye care center. Saudi J Ophthalmol. 2012;26(2):199-203. https://doi.org/10.1016/ j.sjopt.2012.02.007.

16. Fan NW, Wu CC, Chen TL, et al. Microsporidial keratitis in patients with hot springs exposure. J Clin Microbiol. 2012;50(2):414-8. https://doi.org/ 10.1128/JCM.05007-11.

17. Wang WY, Chu HS, Lin PC, et al. Outbreak of Microsporidial keratoconjunctivitis associated with water contamination in swimming pools in Taiwan. Am J Ophthalmol. 2018;194:101-9. https:// doi.org/10.1016/j.ajo.2018.07.019.

18. Dhakal R, Ramappa M, Sharma S. Punctate epithelial keratoconjunctivitis: a microsporidial infestation. Indian J Ophthalmol. 2018. https://doi.org/ 10.4103/ijo.IJO_917_17.

19. Loh RS, Chan CML, Ti SE, Lim L, Chan KS, Tan DTH. Emerging prevalence of Microsporidial keratitis in Singapore. Epidemiology, clinical features, and management. Ophthalmology. 2009. https:// doi.org/10.1016/j.ophtha.2009.05.004.

20. Sabhapandit S, Murthy SI, Garg P, Korwar V, Vemuganti GK, Sharma S. Microsporidial stromal keratitis: clinical features, unique diagnostic criteria, and treatment outcomes in a large case series. Cornea. 2016;35(12):1569-74. https://doi.org/10. 1097/ICO.0000000000000939.

21. Theng J, Chan C, Ling ML, Tan D. Microsporidial keratoconjunctivitis in a healthy contact lens wearer without human immunodeficiency virus infection. Ophthalmology. 2001;108(5):976-8. https://doi.org/10.1016/S0161-6420(01)00542-5.

22. Moon SJ, Mann PM, Matoba AY. Microsporidial keratoconjunctivitis in a healthy patient with a history of LASIK surgery. Cornea. 2003;22(3):271-2. https://doi.org/10.1097/00003226-20030400000020.

23. Pradhan S, Mascarenhas J, Srinivasan M. Microsporidial stromal keratitis masquerading as acute graft rejection. Cornea. 2015;34(3):353-4. https:// doi.org/10.1097/ICO.0000000000000337.
24. Ueno S, Eguchi H, Hotta F, et al. Microsporidial keratitis retrospectively diagnosed by ultrastructural study of formalin-fixed paraffin-embedded corneal tissue: a case report. Ann Clin Microbiol Antimicrob. 2019;18(1):1-5. https://doi.org/10. 1186/s12941-019-0316-y.

25. Jhanji V, Satpathy G, Khokhar S, Agarwal T. Microsporidial keratitis after collagen cross-linking. Ocul Immunol Inflamm. 2013;21(6):495-7. https:// doi.org/10.3109/09273948.2013.824105.

26. Tan J, Lee P, Lai Y, et al. Microsporidial keratoconjunctivitis after rugby tournament, Singapore. Emerg Infect Dis. 2013;19(9):1484-6. https://doi. org/10.3201/eid1909.121464.

27. Kwok AKH, Tong JMK, Tang BSF, Poon RWS, Li WWT, Yuen KY. Outbreak of Microsporidial keratoconjunctivitis with rugby sport due to soil exposure. Eye. 2013;27(6):747-54. https://doi.org/10. 1038/eye.2013.55.

28. Curry A, Mudhar HS, Dewan S, Canning EU, Wagner BE. A case of bilateral microsporidial keratitis from Bangladesh-infection by an insect parasite from the genus Nosema. J Med Microbiol. 2007;56(9):1250-2. https://doi.org/10.1099/jmm.0. 47297-0.

29. Pradhan S, Uddaraju M, Mascarenhas J. Unusual course of microsporidial keratoconjunctivitis as an occupational hazard in a veterinary physician. Can J Ophthalmol. 2016;51(4):e127-9. https://doi.org/ 10.1016/j.jcjo.2016.04.012.

30. Reddy AK, Balne PK, Garg P, Krishnaiah S. Is microsporidial keratitis a seasonal infection in India? Clin Microbiol Infect. 2011;17(7):1114-6. https://doi.org/10.1111/j.1469-0691.2010.03084.x.

31. Das S, Sharma S, Sahu SK, Nayak SS, Kar S. Diagnosis, clinical features and treatment outcome of microsporidial keratoconjunctivitis. Br J Ophthalmol. 2012;96(6):793-5. https://doi.org/10.1136/ bjophthalmol-2011-301227.

32. Ashton N, Wirasinha PA. Encephalitozoonosis (nosematosis) of the cornea. Br J Ophthalmol. 1973. https://doi.org/10.1136/bjo.57.9.669.

33. Gunnarsson G, Hurlbut D, Degirolami PC, Federman M, Wanke C. Multiorgan microsporidiosis: report of five cases and review. Clin Infect Dis. 1995. https://doi.org/10.1093/clinids/21.1.37.

34. Mietz H, Franzen C, Hoppe T, Bartz-Schmidt KU. Microsporidia-induced sclerouveitis with retinal detachment. Arch Ophthalmol. 2002;120:864-5.

35. Yoken J, Forbes B, Maguire AM, Prenner JL, Carpentieri D. Microsporidial endophthalmitis in a 
patient with acute myelogenous leukemia. Retina. 2002 . https://doi.org/10.1097/00006982200202000-00028.

36. Sood AB, Debiec MR, Yeh S, Grossniklaus HE, Randleman JB. Microsporidial stromal keratitis and endophthalmitis in an immunocompetent patient. J Ophthalmic Inflamm Infect. 2016;6(1):10-3. https://doi.org/10.1186/s12348-016-0099-7.

37. Friedberg DN, Stenson SM, Orenstein JM, Tierno PM, Charles NC. Microsporidial keratoconjunctivitis in acquired immunodeficiency syndrome. Arch Ophthalmol. 1990;108(4):504-8. https://doi.org/ 10.1001/archopht.1990.01070060052047.

38. Rosberger DF, Serdarevic LN, Erlandson RA, et al. Successful treatment of microsporidial keratoconjunctivitis with topical fumagillin in a patient with AIDS. Cornea. 1993. https://doi.org/10.1097/ 00003226-199305000-00013.

39. Metcalfe TW, Doran RML, Rowlands PL, Curry A, Lacey CJN. Microsporidial keratoconjunctivitis in a patient with AIDS. Br J Ophthalmol. 1992;76(3): 177-8. https://doi.org/10.1136/bjo.76.3.177.

40. Chan CML, Theng JTS, Li L, Tan DTH. Microsporidial keratoconjunctivitis in healthy individuals: a case series. Ophthalmology. 2003;110(7): $1420-5$. 6420(03)00448-2.

41. Sengupta J, Saha S, Khetan A, Pal D, Gangopadhyay $\mathrm{N}$, Banerjee D. Characteristics of microsporidial keratoconjunctivitis in an eastern indian cohort: a case series. Indian J Pathol Microbiol. 2011. https:// doi.org/10.4103/0377-4929.85094.

42. Agashe R, Radhakrishnan N, Pradhan S, Srinivasan M, Prajna VN, Lalitha P. Clinical and demographic study of microsporidial keratoconjunctivitis in South India: a 3-year study (2013-2015). Br J Ophthalmol. 2017;101(10):1436-9. https://doi.org/10. 1136/bjophthalmol-2016-309845.

43. Hsiao YC, Tsai IL, Kuo CT, Yang TL. Diagnosis of microsporidial keratitis with in vivo confocal microscopy. J Xray Sci Technol. 2013;21(1):103-10. https://doi.org/10.3233/XST-130357.

44. Fan NW, Lin PY, Chen TL, Chen CP, Lee SM. Treatment of microsporidial keratoconjunctivitis with repeated corneal swabbing. Am J Ophthalmol. 2012;154(6):927.e1-933.e1. https://doi.org/10. 1016/j.ajo.2012.06.002.

45. Thanathanee O, Laohapitakvorn S, Anutarapongpan O, Suwan-Apichon O, Bhoomibunchoo C. Anterior segment optical coherence tomography images in Microsporidial keratoconjunctivitis.
Cornea. 2019;38(8):943-7. https://doi.org/10.1097/ ICO.0000000000001994.

46. Malhotra C, Jain AK, Kaur S, Dhingra D, Hemanth $\mathrm{V}$, Sharma SP. In vivo confocal microscopic characteristics of microsporidial keratoconjunctivitis in immunocompetent adults. $\mathrm{Br} \mathrm{J}$ Ophthalmol. 2017;101(9):1217-22. https://doi.org/10.1136/ bjophthalmol-2016-309794.

47. Thomas KE, Purcell TL, Tanzer DJ, Schanzlin DJ. Delayed diagnosis of microsporidial stromal keratitis: unusual wessely ring presentation and partial treatment with medications against Acanthamoeba. BMJ Case Rep. 2011;2011:2010-2. https://doi.org/10.1136/bcr.08.2010.3233.

48. Schwartz DA, Visvesvara GS, Diesenhouse MC, et al. Pathologic features and immunofluorescent antibody demonstration of ocular microsporidiosis (Encephalitozoon hellem) in seven patients with acquired immunodeficiency syndrome. Am J Ophthalmol. 1993. https://doi.org/10.1016/S00029394(14)73577-9.

49. Weber R, Bryan RT, Visvesvara GS, Owen RL, Wilcox CM, Gorelkin L. Improved light-microscopical detection of microsporidia spores in stool and duodenal aspirates. N Engl J Med. 1992. https://doi. org/10.1056/NEJM199201163260304.

50. Joseph J, Sharma S, Murthy SI, et al. Microsporidial keratitis in India: 16s rRNA gene-based PCR assay for diagnosis and species identification of microsporidia in clinical samples. Investig Ophthalmol Vis Sci. 2006;47(10):4468-73. https://doi.org/10. 1167/iovs.06-0376.

51. Gillespie SH, Pearson RD. Principles and practice of clinical parasitology principles and practice of clinical parasitology. Hoboken: Wiley; 2001.

52. Raynaud L, Delbac F, Broussolle V, et al. Identification of Encephalitozoon intestinalis in travelers with chronic diarrhea by specific PCR amplification. J Clin Microbiol. 1998;36:37-40.

53. Müller A, Stellermann K, Hartmann $\mathrm{P}$, et al. A powerful DNA extraction method and PCR for detection of microsporidia in clinical stool specimens. Clin Diagn Lab Immunol. 1999;6:243-6.

54. Polley SD, Boadi S, Watson J, Curry A, Chiodini PL. Detection and species identification of microsporidial infections using SYBR Green real-time PCR. J Med Microbiol. 2011. https://doi.org/10. 1099/jmm.0.026781-0.

55. Sagoo MS, Mehta JS, Hau S, et al. Microsporidium stromal keratitis: in vivo confocal findings. Cornea. 2007;26(7):870-3. https://doi.org/10.1097/ICO. 0b013e31806c7a3c. 
56. Tham AC, Sanjay S. Clinical spectrum of microsporidial keratoconjunctivitis. Clin Exp Ophthalmol. 2012. https://doi.org/10.1111/j.1442-9071. 2011.02712.x.

57. Franssen FFJ, Lumeij JT, Van Knapen F. Susceptibility of Encephalitozoon cuniculi to several drugs in vitro. Antimicrob Agents Chemother. 1995. https://doi.org/10.1128/AAC.39.6.1265.

58. Gritz DC, Holsclaw DS, Neger RE, Whitcher J, Margolis TP. Ocular and sinus microsporidial infection cured with systemic albendazole. Am J Ophthalmol. 1997. https://doi.org/10.1016/S00029394(14)70792-5.

59. Didier ES, Maddry JA, Brindley PJ, Stovall ME, Didier PJ. Therapeutic strategies for human microsporidia infections. Expert Rev Anti Infect Ther. 2005. https://doi.org/10.1586/14787210.3.3.419.

60. Sridhar MS, Shaik B. Anterior segment optical coherence tomography of Microsporidial keratoconjunctivitis. Indian J Ophthalmol. 2018. https:// doi.org/10.4103/ijo.IJO_1005_17.

61. Devi L, Prajna N, Srinivasan M, Radhakrishnan N, Das M. Microsporidial infection masquerading as graft rejection post-Descemet's stripping automated endothelial keratoplasty. Indian J Ophthalmol. 2017. https://doi.org/10.4103/ijo.IJO_295_17.

62. Khandelwal SS, Woodward MA, Hall T, Grossniklaus HE, Stulting RD. Treatment of microsporidia keratitis with topical voriconazole monotherapy. Arch Ophthalmol. 2011. https://doi. org/10.1001/archophthalmol.2011.54.

63. Sridhar MS, Sharma S. Microsporidial keratoconjunctivitis in a HIV-seronegative patient treated with debridement and oral itraconazole. Am J Ophthalmol. 2003;136(4):745-6. https://doi.org/ 10.1016/S0002-9394(03)00391-X.

64. Rossi P, Urbani C, Donelli G, Pozio E. Resolution of Microsporidial sinusitis and keratoconjunctivitis by itraconazole treatment. Am J Ophthalmol. 1999;127(2):210-2. https://doi.org/10.1016/S00029394(98)00352-3.

65. Mc Cluskey PJ, Goonan PV, Marriott DJE, Field AS. Microsporidial keratoconjunctivitis in AIDS. Eye. 1993. https://doi.org/10.1038/eye.1993.17.

66. Das S, Sahu SK, Sharma S, Nayak SS, Kar S. Clinical trial of $0.02 \%$ polyhexamethylene biguanide versus placebo in the. Am J Ophthalmol. 2010;150(1):110. e2-115.e2. https://doi.org/10.1016/j.ajo.2010.01. 038.

67. Das S, Wallang BS, Sharma S, Bhadange YV, Balne PK, Sahu SK. The efficacy of corneal debridement in the treatment of Microsporidial keratoconjunctivitis: a prospective randomized clinical trial. Am J Ophthalmol. 2014;157(6):1151-5. https://doi.org/ 10.1016/j.ajo.2014.02.050.

68. Coca M, Kim J, Shenoy S, Chévez-Barrios P, Kapur M. Microsporidial stromal keratitis: successful treatment with topical voriconazole and oral itraconazole. Cureus. 2016;8(12):8-12. https://doi.org/ $10.7759 /$ cureus.934.

69. Sangit VA, Murthy SI, Garg P. Microsporidial stromal keratitis successfully treated with medical therapy: a case report. Cornea. 2011. https://doi. org/10.1097/ICO.0b013e31821d876d.

70. Grillo LM, Epstein IJ, Donnenfeld ED, Perry HD. Late-onset microsporidial keratitis in femtosecond astigmatic keratotomy after laser-assisted phacoemulsification. Cornea. 2018;37(11):1471-3. https://doi.org/10.1097/ICO.0000000000001743.

71. Garg P. Microsporidia infection of the cornea-a unique and challenging disease. Cornea. 2013. https://doi.org/10.1097/ICO.0b013e3182a2c91f.

72. Ang M, Mehta JS, Mantoo S, Tan D. Deep anterior lamellar keratoplasty to treat microsporidial stromal keratitis. Cornea. 2009;28(7):832-5. https:// doi.org/10.1097/ico.0b013e3181930ddc. 